\title{
Matrix metalloproteinase-2 and -9 in the sera and in the urine of human oncocytoma and renal cell carcinoma
}

\author{
ANGELINA DI CARLO \\ Department of Medico-Surgical Sciences and Biotechnologies, 'Sapienza' University of Rome, I-00161 Rome, Italy
}

Received March 29, 2012; Accepted May 2, 2012

DOI: 10.3892/or.2012.1864

\begin{abstract}
Matrix metalloproteinases (MMPs) are a family of zinc-dependent endopeptidases, capable of degrading all the molecular components of extracellular matrix. MMPs have been shown to play critical roles in tumor cell invasion and metastasis. We verified the activity of MMPs in the sera and in the urine of patients with kidney carcinoma by gelatin zymography. Of these patients, 16 had clear cell renal carcinoma (ccRCC) and 4 patients had oncocytoma. The sera and the urine of 16 healthy subjects were used as controls. In the sera, zymography analysis showed gelatinolytic bands at $72 \mathrm{kDa}$ (gelatinase A) at 92,130 and $240 \mathrm{kDa}$ (gelatinase B). MMP-9 activity was slightly enhanced in sera from ccRCC compared with oncocytoma patients. Serum MMP-2 activity was similar in ccRCC and in oncocytoma patients. In the urine, 2 oncocytoma patients and $3(33 \%)$ of the ccRCC patients showed gelatinolytic activity, whereas MMPs could not be detected in the concentrated urine of healthy subjects. The most abundant lytic activity was at $92 \mathrm{kDa}$, whereas MMP-2 was present in lesser quantities. However, there was broad overlap of the data and we did not find any correlation to type, stage or grade. Therefore, despite previous evidence, MMP-2 and -9 activity in serum and urine may not be useful biomarker for kidney carcinomas.
\end{abstract}

\section{Introduction}

Kidney tumors may be benign or malignant. Benign tumors are incidentally findings at autopsy and are rarely of clinical significance with the exception of oncocytoma. On the other hand, malignant tumors arise from renal epithelial cells and are of great clinical importance. They are the third most common malignancy of the urinary tract after prostate and bladder cancer (1). The renal cell carcinomas (RCC) can be pathologically classified into subtypes: the clear cell type,

Correspondence to: Professor Angelina Di Carlo, Department of Medical Surgical Sciences and Biotechnologies, Corso della Repubblica 79, I-04100 Latina, Italy

E-mail: angelina.dicarlo@uniroma1.it

Key words: matrix metalloproteinase-2, matrix metalloproteinase-9, oncocytoma, clear cell renal cell carcinoma, urine, serum which constitutes $80 \%$ of all cases, the papillary type, at around $15 \%$ and the remaining $5 \%$ of other histological types (chromophobe, collecting duct and unclassified RCC). The subtype chromophobe RCC cases have a better prognosis compared to those of clear cell RCC (ccRCC) due to the high incidence of cell invasion in the ccRCC subtype. Early stage RCC is relatively asymptomatic, and the classical triad of flank pain, hematuria and of renal mass only manifests very late in the course of the disease. The diagnosis is confirmed with imaging studies, and many cases are now accidentally discovered during routine imaging. Moreover, kidney biopsy is an invasive technique that may result in complications and will not be able to provide accurate diagnosis in certain situations (2). Therefore, there is a pressing need for non-invasive methods to diagnose carcinoma of the kidney as well as for follow-up surveillance.

Matrix metalloproteinases (MMPs) form a family of $>25$ endopeptidases known to degrade extracellular matrix and basal membrane. MMPs depend on a $\mathrm{Zn}^{2+}$ ion to degrade components of the extracellular matrix such as fibrillar and non-fibrillar collagen, proteoglycans, glycoproteins and denatured collagen. Furthermore, MMPs are involved in direct and indirect release of growth factors enhancing tumor growth and tumorigenicity. In particular, the ability to degrade type IV collagen, the major component of the basement membrane, is unique to MMP-2 and MMP-9 also known as gelatinase A $(72 \mathrm{kDa})$ and gelatinase $\mathrm{B}(92 \mathrm{kDa})$, respectively. These two MMPs are most often linked to the malignant phenotype of tumor cells, and are commonly used as markers of malignant cancer (3-5).

In the present study, we determined MMP-2 and MMP-9 activity levels in sera and urine from patients with oncocytoma and clear renal cell carcinoma using gelatin zymography in order to analyze the pattern of gelatinolityc activities and to verify whether they may have potential as non-invasive biomarker in providing useful clinical information in kidney cancer.

\section{Materials and methods}

Patients. Peripheral venous blood samples and first morning urine were collected from patients before surgical or other therapeutic intervention.

Specimens were obtained from patients who underwent surgical procedure. Diagnosis of tumors was made by usual 
clinical laboratory criteria and confirmed postoperatively by histopathological findings. The age of the patients was between 40 and 73 years (mean \pm SD, 59.2 \pm 9.7 ) and there were 11 males and 19 females. The tumors were classified for grade and stage according to the pTNM classification (6). All patients provided written informed consent. The study was approved by the local ethics committee. Sixteen healthy volunteers with no concomitant illnesses were used as controls. The age of the healthy volunteers was between 30 and 70 years (mean \pm SD, 57 \pm 11 ) and there were 9 males and 7 females. Healthy volunteers gave their permission verbally. The subjects in the controls had no sign of infections, gastrointestinal hepatic or renal disease, tumors or immunologic disease. The values of the basic laboratory parameters of these participants were within the reference limits.

Serum. Native serum was prepared using plastic tubes without coagulation accelerators, to prevent the release of gelatinase during platelet activation. Tubes were centrifuged at $1600 \mathrm{xg}$ for $10 \mathrm{~min}, 30 \mathrm{~min}$ after blood collection. For each sample, determination of protein concentration was performed using the Bradford method (7). Sera were aliquoted and stored at $-20^{\circ} \mathrm{C}$ until used. Each aliquot was used only once in order to prevent enzyme activation due to freeze-thawing processes.

Urine sample preparation. Prior to analysis, urine samples were tested using Multistix Combur test (Roche Diagnostic GmbH, Mannheim). Urine samples positive for leukocytes were excluded because of confounding leukocytic gelatinases. Microscopic hematuria present in most cancer samples was not quantified but grossly hematuric samples were excluded. Samples were frozen immediately after collection and stored frozen $\left(-20^{\circ} \mathrm{C}\right)$ until assay. The samples were thawed and an aliquot of each sample $(15 \mathrm{ml})$ were centrifuged at $1000 \mathrm{xg}$ for $10 \mathrm{~min}$ at $4^{\circ} \mathrm{C}$.

An aliquot of the supernatant of each sample $(2 \mathrm{ml})$ was concentrated by ultrafiltration using Vivaspin 2 spin column membrane molecular weight cut-off (MWCO): Mr 30000 according to manufacturer's instructions (Sartorius Stedim Biotech $\mathrm{GmbH}$, Goettingen, Germany). An aliquot (12 $\mu \mathrm{l})$ of concentrate urine was used to determine MMP-2 and MMP-9 by gelatin zymography.

Materials. Gelatinase A and gelatinase B were purchesed from Hoffmann-La Roche Ltd (Basel, Switzerland). Calcium chloride $\left(\mathrm{CaCl}_{2}\right)$ glycerol, gelatin, ethylenediaminetetraacetic (EDTA), Triton X-100, phenylmethylsulphonyl fluoride (PMSF) were from Sigma Chemical Co. (St. Louis, MO, USA). Ultra filtration spin columns were from Sartorius Stedim Biotech GmbH. All other reagents were available from commercial sources.

Gelatin zymography. Zymography was performed using $7.5 \%$ $(\mathrm{w} / \mathrm{v})$ polyacrylamide gels containing $0.1 \%(\mathrm{w} / \mathrm{v})$ of gelatine as previously described $(8,9)$. Briefly, serum samples or concentrated urine samples were mixed with sample buffer $(10 \mathrm{mM}$ Tris-HCl pH 6.8, $12.5 \%$ SDS, $5 \%$ sucrose, $0.1 \%$ bromophenol blue) and applied directely without prior heating or reduction to the gel. After removal of SDS from the gel by incubation in $2.5 \%(\mathrm{v} / \mathrm{v})$ Triton X-100 for $1 \mathrm{~h}$, the gels were incubated at $37^{\circ} \mathrm{C}$ for $18 \mathrm{~h}$ in $50 \mathrm{mM}$ Tris- $\mathrm{HCl} \mathrm{pH} 7.6$ containing $0.2 \mathrm{M}$ $\mathrm{NaCl}, 5 \mathrm{mM} \mathrm{CaCl}_{2}$ and $0.02 \%$ (w/v) Brij 35. Gels were stained

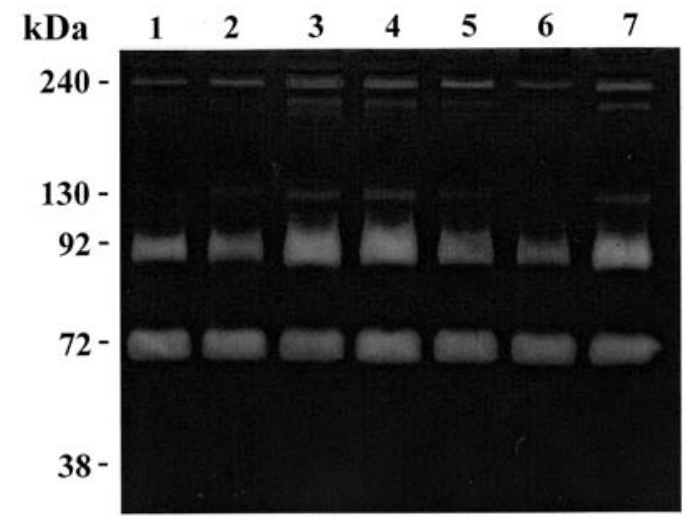

Figure 1. Gelatin zymography of serum specimens from patients with oncocytoma and ccRCC. Molecular weights standards are shown on the left. In all serum sample $25 \mu \mathrm{g}$ of protein was loaded onto the gel. Lane 1, oncocytoma T2N0M0 G1 in presence of $2 \mathrm{mM}$ Pefabloc (patient P3); lane 2, oncocytoma T1N0M0 G1 (patient P2); lane 3, ccRCC T3N0M0 G3 (patient P20); lane 4 ccRCC T2N0M0 G2 (patient P13); lane 5, ccRCC T1N0M0 G2) (patient P7); lane 6, oncocytoma T2N0M0 G1 (patient P3); lane 7, oncocytoma T1N0M0 G1 (patient P4).

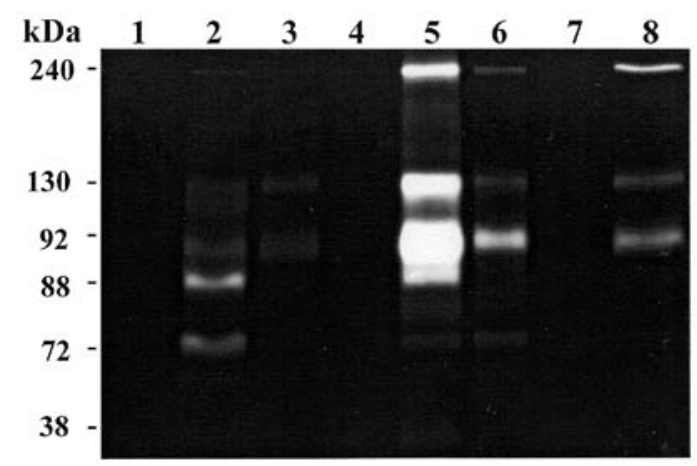

Figure 2. Gelatin zymography of urine specimens from patients with oncocytoma and ccRCC. Molecular weights standards are shown on the left. Lane 1, oncocytoma T1N0M0 G1 (patient P4); lane 2, ccRCC T2N0M0 G3 (patient P15); lane 3, ccRCC T1N0M0 G1 (patient P5); lane 4, ccRCC T1N0M0 G2 (patient P9) in the presence of 1,10 phenanthroline $10 \mathrm{mM}$; lane 5, ccRCC T1N0M0 G2 (patient P9); lane 6, oncocytoma T1N0M0 G1 (patient P1): lane 6, oncocytoma (patient P1); lane 7 ccRCC T3N0M0 G3 (patient P20); lane 8 ccRCC T1N0M0 G2 (patient P7).

for $1 \mathrm{~h}$ in $30 \%$ methanol, $10 \%$ glacial acetic acid containing $0.5 \%(\mathrm{w} / \mathrm{v})$ Coomassie Brilliant Blue G-250 and destained in the same solution without dye for several hours. The gelatinolytic activity of each collagenase was evident as a clear band against the blue background of stained gelatin. The molecular size of bands displaying enzymatic activity were identified by comparison with prestained standard protein, as well as with purified gelatinase A or gelatinase B. To normalize the possible difference between zymograms an internal serum or urine sample from a patient was incorporated in every gel.

Control gels for MMPs. Control gels contained either of the MMP selective inhibitors, $20 \mathrm{mM}$ EDTA or $10 \mathrm{mM} 1,10$ phenanthroline, in the MMP incubation buffer to confirm that the lysis band was the result of MMPs. Furthermore, the character of proteolytic bands was analyzed by incubating the identical zymograms in $0.1 \mathrm{mg} / \mathrm{ml}$ of PMSF, a serine protease 
Table I. Serum MMP content in healthy subjects.

Volume $\times 10^{-3}$

\begin{tabular}{lcccccc}
\cline { 4 - 6 } Case & Age (years) & Gender & MMP (240 kDa) & MMP (130 kDa) & MMP (92 kDa) & MMP (72 kDa) \\
\hline H1 & 58 & F & 340 & 0 & 554 & 456 \\
H2 & 54 & M & 186 & 0 & 507 & 455 \\
H3 & 63 & M & 119 & 33 & 663 & 440 \\
H4 & 67 & F & 175 & 0 & 749 & 520 \\
H5 & 55 & M & 88 & 0 & 367 & 142 \\
H6 & 61 & M & 0 & 0 & 785 & 414 \\
H7 & 34 & M & 30 & 0 & 710 & 294 \\
H8 & 70 & M & 51 & 69 & 775 & 127 \\
H9 & 44 & M & 281 & 115 & 577 & 161 \\
H10 & 56 & F & 235 & 73 & 538 & 250 \\
H11 & 43 & F & 267 & 87 & 642 & 128 \\
H12 & 68 & M & 36 & 106 & 515 & 408 \\
H13 & 65 & F & 85 & 18 & 659 & 296 \\
H14 & 64 & F & 334 & 117 & 505 & 893 \\
H15 & 69 & F & 141 & 67 & 746 & 501 \\
H16 & 39 & M & 263 & 86 & 532 & 630 \\
\hline
\end{tabular}

Table II. Serum MMP content in oncocytoma.

\begin{tabular}{lcccccrrr}
\hline & & & & & \multicolumn{4}{c}{ Volume x10 $^{-3}$} \\
\cline { 5 - 8 } Case & $\begin{array}{c}\text { Age } \\
\text { (years) }\end{array}$ & Gender & Stage & Grade & $\begin{array}{c}\text { MMP } \\
(240 \mathrm{kDa})\end{array}$ & $\begin{array}{c}\text { MMP } \\
(130 \mathrm{kDa})\end{array}$ & $\begin{array}{c}\text { MMP } \\
(92 \mathrm{kDa})\end{array}$ & $\begin{array}{c}\text { MMP } \\
(72 \mathrm{kDa})\end{array}$ \\
\hline P1 & 42 & F & T1N0M0 & G1 & 208 & 147 & 1259 & 1125 \\
P2 & 66 & M & T1N0M0 & G1 & 19 & 6 & 133 & 190 \\
P3 & 59 & F & T2N0M0 & G1 & 12 & 0 & 98 & 175 \\
P4 & 59 & F & T1N0M0 & G1 & 28 & 14 & 229 & 183 \\
\hline
\end{tabular}

inhibitor; or $2 \mathrm{mM}$ Pefabloc, an irreversible serine protease inhibitor.

Analysis of the gels. Following zymography, the degree of gelatin digestion was quantified as previously described. Briefly, we used an image analysis software (ImageQuant TL, Amersham Bioscience, Chicago, IL, USA) according to the manufacturer's specifications. The image of the gel was inverted to reveal dark bands on a white background. The molecular weight, volume and background of each band were determined. The relative amounts of the different forms of both serum and urine gelatinases were expressed as the integrated density $\times 10^{-3}$ (volume) of all the pixels above the background of each band.

\section{Results}

During a 1-year period a total of 20 patients with kidney disease were evaluated. Of these patients, 4 had oncocytoma and 16 had clear cell renal carcinoma (ccRCC). All patients provided venous blood samples; among these the 4 patients with oncocytoma and 9 patients with ccRCC collected their first morning urine.

To investigate the gelatinolytic activity present in the serum and in concentrate urine, substrate gel zymography was performed. This method allows the detection of the metalloproteinases that exhibit gelatinolytic activity (gelatinase A and B). Representative zymography results are shown in Figs. 1 and 2. Polyacrylamide gels were evaluated for the presence of clear zone representing degradation of gelatine by proteolysis. The nature of lytic bands was confirmed by inhibition assay with a selective inhibitor of serine proteases (Fig. 1, lane 1) and with selective inhibitors of MMPs (Fig. 2, lane 4). In the sera of all patients, the gels revealed the existence of four clear zones representing degradation of gelatin by proteolysis migrating at approximately 240, 130, $92 \mathrm{kDa}$ (MMP-9) and $72 \mathrm{kDa}$ (MMP-2), respectively. Comparison of these gelatinolytic bands with prestained standard protein and purified gelatinase A (MMP-2) and gelatinase B (MMP-9) clearly identified the MMP-constituting bands as gelatinase A (MMP-2; $72 \mathrm{kDa}$ ) and gelatinase B (MMP-9; $92 \mathrm{kDa})$. The clear zones 


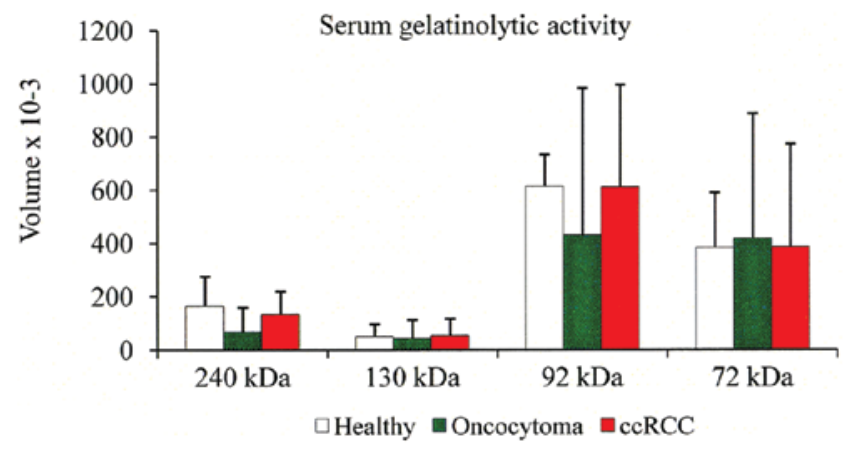

Figure 3. Mean expression + SD of serum matrix metalloproteinases.

with molecular weight $>92 \mathrm{kDa}$ might represent complexes of MMPs that are not dissociated in zymography. In fact, MMP-9 can be associated with a 25-kDa protein (lipocalin) giving a band at $\sim 125 \mathrm{kDa}(10,11)$ and can form a complex with its endogenous inhibitors TIMP-1 giving a band at $\sim 140 \mathrm{kDa}$ (12). Furthermore, MMP-9 can form dimer or multidimer giving lytic bands at approximately 215 and $240 \mathrm{kDa}$ (13). Also, several MMPs together can form complexes of high molecular weight (HMW) gelatinase species that can only be identified with specific antibodies in western blot analysis. However, because zymography is much more sensitive than western blot analysis, it has been difficult to find antibodies that were sensitive enough to detect small amounts of MMPs.

Following gelatin zymography, the proteolytic bands were subjected to densitometric analysis and the data, normalized to an internal serum standard, were expressed as the integrated density of all the pixels of each band (volume $\times 10^{-3}$ ). A summary of expression patterns of each proteinase is shown in

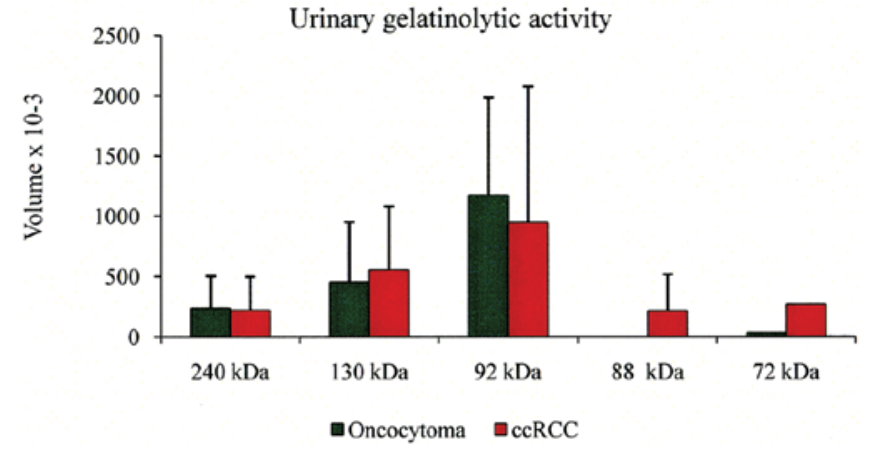

Figure 4. Mean expression + SD of urinary matrix metalloproteinases.

the tables. Considering the volume average of each individual band, we observed that the $92 \mathrm{kDa}$ band is slightly higher in the sera from ccRCC patients compared with that of oncocytoma patients. The second point is that the serum $72 \mathrm{kDa}$ band is similar both in ccRCC and oncocytoma patients as well as in normal individuals (Fig. 3).

As it concerns urine specimens, gelatin zymography identified that MMPs were present in the concentrate urine of 2 oncocytoma patients and in 3 out of $9(33 \%)$ of ccRCC patients (Tables IV and V), whereas MMP could not be detected in the concentrate urine of healthy subjects with no evidence of disease (data not shown). In the oncocytoma group, one sample (patient P1) showed faint small lytic bands at 240,130 and $72 \mathrm{kDa}$ and a more strong lytic band at $92 \mathrm{kDa}$ (Fig. 2, lane 6 and Table IV). Another sample (patient P3, T2NOM0, G1) showed a more intense lytic activity at 240, 130 and $92 \mathrm{kDa}$ with a value of 425,805 and 1749 , respectively and no lytic band at $72 \mathrm{kDa}$ (Table IV). Regarding ccRCC patients, 2 specimens

Table III. Serum MMP content in clear cell renal carcinoma.

\begin{tabular}{|c|c|c|c|c|c|c|c|c|}
\hline \multirow[b]{2}{*}{ Case } & \multirow[b]{2}{*}{$\begin{array}{c}\text { Age } \\
\text { (years) }\end{array}$} & \multirow[b]{2}{*}{ Gender } & \multirow[b]{2}{*}{ Stage } & \multirow[b]{2}{*}{ Grade } & \multicolumn{4}{|c|}{ Volume $\times 10^{-3}$} \\
\hline & & & & & $\begin{array}{c}\text { MMP } \\
(240 \mathrm{kDa})\end{array}$ & $\begin{array}{c}\text { MMP } \\
(130 \mathrm{kDa})\end{array}$ & $\begin{array}{c}\text { MMP } \\
(92 \mathrm{kDa})\end{array}$ & $\begin{array}{c}\text { MMP } \\
(72 \mathrm{kDa})\end{array}$ \\
\hline P5 & 69 & M & T1N0M0 & G1 & 183 & 24 & 1153 & 1017 \\
\hline P6 & 54 & $\mathrm{M}$ & T1N0M0 & G1 & 94 & 29 & 463 & 100 \\
\hline P7 & 53 & M & T1N0M0 & $\mathrm{G} 2$ & 23 & 7 & 160 & 188 \\
\hline P8 & 60 & $\mathrm{~F}$ & T1N0M0 & $\mathrm{G} 2$ & 135 & 0 & 632 & 791 \\
\hline P9 & 51 & $\mathrm{~F}$ & T1N0M0 & $\mathrm{G} 2$ & 295 & 215 & 1151 & 1070 \\
\hline P10 & 63 & F & T1N0M0 & G2 & 237 & 124 & 1185 & 913 \\
\hline P11 & 63 & $\mathrm{M}$ & T2N0M0 & $\mathrm{G} 2$ & 125 & 40 & 343 & 113 \\
\hline P12 & 60 & $\mathrm{~F}$ & T2N0M0 & G2 & 128 & 73 & 634 & 105 \\
\hline P13 & 40 & $\mathrm{M}$ & T2N0M0 & G3 & 29 & 15 & 241 & 207 \\
\hline P14 & 73 & M & T2N0M0 & G3 & 87 & 0 & 558 & 107 \\
\hline P15 & 70 & M & T2N0M0 & G3 & 279 & 168 & 1341 & 886 \\
\hline P16 & 61 & M & T2N0M0 & G3 & 117 & 47 & 623 & 114 \\
\hline P17 & 73 & $\mathrm{~F}$ & T2N0M0 & G3 & 221 & 47 & 432 & 97 \\
\hline P19 & 43 & M & T2N0M0 & G3 & 99 & 45 & 411 & 117 \\
\hline P19 & 67 & M & T3N0M1 & G3 & 34 & 9 & 214 & 186 \\
\hline P20 & 57 & $\mathrm{~F}$ & T3bN0M1 & G3 & 35 & 13 & 253 & 179 \\
\hline
\end{tabular}


Table IV. Urine MMP content in oncocytoma.

\begin{tabular}{lcccccrcr}
\hline & & & & & \multicolumn{4}{c}{ Volume x10 $^{-3}$} \\
\cline { 6 - 8 } Case & $\begin{array}{c}\text { Age } \\
\text { (years) }\end{array}$ & Gender & Stage & Grade & $\begin{array}{c}\text { MMP } \\
(240 \mathrm{kDa})\end{array}$ & $\begin{array}{c}\text { MMP } \\
(130 \mathrm{kDa})\end{array}$ & $\begin{array}{c}\text { MMP } \\
(92 \mathrm{kDa})\end{array}$ & $\begin{array}{c}\text { MMP } \\
(72 \mathrm{kDa})\end{array}$ \\
\hline P1 & 42 & F & T1N0M0 & G1 & 48 & 98 & 602 & 34 \\
P2 & 66 & M & T1N0M0 & G1 & 0 & 0 & 0 & 0 \\
P3 & 59 & F & T2N0M0 & G1 & 425 & 805 & 1749 & 0 \\
P4 & 59 & F & T1N0M0 & G1 & 0 & 0 & 0 & 0 \\
\hline
\end{tabular}

Table V. Urine MMP content in clear cell renal carcinoma.

\begin{tabular}{|c|c|c|c|c|c|c|c|c|c|}
\hline \multirow[b]{2}{*}{ Case } & \multirow[b]{2}{*}{$\begin{array}{c}\text { Age } \\
\text { (years) }\end{array}$} & \multirow[b]{2}{*}{ Gender } & \multirow[b]{2}{*}{ Stage } & \multirow[b]{2}{*}{ Grade } & \multicolumn{5}{|c|}{ Volume $\times 10^{-3}$} \\
\hline & & & & & $\begin{array}{c}\text { MMP } \\
(240 \mathrm{kDa})\end{array}$ & $\begin{array}{c}\text { MMP } \\
(130 \mathrm{kDa})\end{array}$ & $\begin{array}{c}\text { MMP } \\
(92 \mathrm{kDa})\end{array}$ & $\begin{array}{c}\text { MMP } \\
(88 \mathrm{kDa})\end{array}$ & $\begin{array}{c}\text { MMP } \\
(72 \mathrm{kDa})\end{array}$ \\
\hline P5 & 69 & M & T1N0M0 & G1 & 0 & 0 & 0 & 0 & 0 \\
\hline P6 & 54 & M & T1N0M0 & G1 & 0 & 0 & 0 & 0 & 0 \\
\hline P7 & 53 & M & T1N0M0 & G2 & 91 & 180 & 418 & 0 & 0 \\
\hline P9 & 51 & $\mathrm{~F}$ & T1N0M0 & G2 & 540 & 927 & 2246 & 26 & 0 \\
\hline P13 & 40 & M & T2N0M0 & G3 & 0 & 0 & 0 & 0 & 0 \\
\hline P14 & 73 & M & T2N0M0 & G3 & 0 & 0 & 0 & 0 & 0 \\
\hline P15 & 70 & M & T2N0M0 & G3 & 23 & 0 & 181 & 430 & 270 \\
\hline P19 & 67 & M & T3N0M1 & G3 & 0 & 0 & 0 & 0 & 0 \\
\hline $\mathrm{P} 20$ & 57 & $\mathrm{~F}$ & T3bN0M1 & G3 & 0 & 0 & 0 & 0 & 0 \\
\hline
\end{tabular}

showed a lytic band at $88 \mathrm{kDa}$ (active MMP-9) presumably due to an autoactivation during renaturation period. In particular, case P9 (T1N0M0, G2) (Fig. 2, lane 5) showed very strong lytic

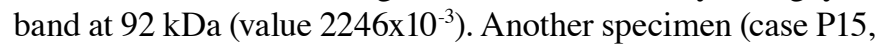
T2N0M0, G3) (Fig. 2, lane 2) showed a very faint lytic band at $240 \mathrm{kDa}$, a lytic activity at $92 \mathrm{kDa}$ (value $181 \times 10^{-3}$ ) and a more strong lytic band at $88 \mathrm{kDa}$ (value $430 \times 10^{-3}$ ). Furthermore, this patient showed lytic activity at $72 \mathrm{kDa}$ (value $270 \times 10^{-3}$ ), whereas all the other specimens showed no activity at $72 \mathrm{kDa}$ (Table V). The volume average of each individual band of the positive urine specimens is shown in Fig. 4. It is evident that the most abundant lytic activity was at $92 \mathrm{kDa}$ band. Finally, specimens P19 (T3N0M1, G3) and P20 (T3bNOM1) had metastasis in the bony skeleton. We found that the serum lytic activity of these patients was not increased compared with the serum levels in healthy subjects as well as with those of cancer patients. Moreover, in the concentrate urine of these patients we did not find any gelatinolytic activity (Tables III and V).

\section{Discussion}

Due to its asymptomatic clinical course RCC is being detected incidentally in two-thirds of patients (14). Therefore, the diagnosis of RCC is a critical issue in the management of the patients. One of the strategies to improve this situation is the identification of biomarkers in serum or urine samples whose levels are sensitive to detect tumor forms and to monitor for disease progression.
Several tumor markers have been tested in the past, but there are no definitive biomarkers available for such purpose (15). Among protein markers, MMP-2 and MMP-9 have been investigated with variable results. Tissue MMP-2 and MMP-9 were found to be overexpressed in tumors and more frequently in non-ccRCC $(16,17)$. In particular, by immunochemistry Kallakury et al (17) found overexpression of MMP-2 and MMP-9 in 43\% of tumors and this increased expression correlated with poor prognostic variables. Moreover, by immunostaining Abdel-Wahed et al found a positive correlation between MMP-2 expression and tumor size, histologic type and high levels of cellular proliferation (18). However, although these studies on tissue markers are highly promising, there are some limitations. In fact, immunochemistry is semi-quantitative and highly dependent on a range variables such as choice of antibody, antibody concentration, fixation techniques, variability in the interpretation and stratification criteria, and inconsistency in specimens handling and technical procedures. Using the RT-PCR technique, Kugler et al analyzed MMP-2 and-9 and their inhibitors in 17 RCC patients and demonstrated a strong correlation between increased gene expression and tumor stage and aggressiveness (19). By in situ zymography, Kamiya et al found that the lytic activity is higher at the peripheries of tumors in inflammatory sites (20). As it concerns peripheral blood, Lein et al measured MMP-2 and -9 and their inhibitors using ELISA technique in 36 RCC patients and found that plasma MMP-2 levels were higher in healthy controls, whereas MMP-9 concentrations 
were significantly higher in RCC patients than in healthy controls with a sensitivity of only $36 \%$ in detecting RCC and found no correlation with tumor type, grade or stage (21). The results shown here indicate that MMP-2 (72 kDa lytic band) and MMP-9 (92 kDa lytic band) are present in the sera of all the patients analyzed. The mean values of MMP- 2 are similar in ccRCC and oncocytoma patients, whereas the mean values of MMP-9 are slightly higher in ccRCC patients compared with those of oncocytoma patients. However, there was a broad overlap of the data and we found no correlation to type of carcinoma, pathological TNM stage or histological grading.

The idea to follow localized tumors or to monitor drugbased therapy results by simply analyzing tumor-specific markers in the easily available excretory product of the kidney is desirable. However, to the best of our knowledge there is only scant literature on urine markers for RCC. In the urine samples, we found that only few specimens have lytic activity. Our data are in keeping with the data of Cannon and Getzenberg (22) but in contrast with those of Sherief et al (23).

So far, despite the tissue evidence, serum and urine MMP activities seem to be not an adequate test to identify renal cancer. Nevertheless, due to the small number of patients included in the studies, the conclusion may not be transferable to the general population and therefore merits further evaluation. Future investigation involving gelatine zymography in larger cohorts of patients could clear up if MMP-2 and MMP-9 are useful biomarkers for RCC.

\section{References}

1. Jemal A, Siegel R, Xu J and Ward E: Cancer statistics, 2010. CA Cancer J Clin 60: 277-300, 2010.

2. Cohen HT and McGoven FJ: Renal-cell carcinoma. N Engl J Med 353: 2477-2490, 2005.

3. Nagase $\mathrm{H}$ and Woessner JF: Matrix metalloproteinases. J Biol Chem 274: 21491-21494, 1999.

4. Egeblad M and Werb Z: New functions for the matrix metalloproteinases in cancer progression. Nat Rev Cancer 2: 161-174, 2002.

5. Björklund M and Koivunen E: Gelatinase-mediated migration and invasion of cancer cell. Biochim Biophys Acta 1755: 37-69, 2005.

6. Sobin LH and Wittekind $\mathrm{CH}$ (eds): International Union Against Cancer (UICC) TNM classification of malignant tumors. 6th edition. Wiley-Liss, New York, NY, pp193-195, 2002.

7. Bradford MM: A rapid and sensitive method for quantitation of microgram quantities of protein utilizing the principle of proteindye binding. Anal Biochem 72: 248-254, 1976.

8. Di Carlo A, Terracciano D, Mariano A and Macchia V: Urinary gelatinase activities (matrix metalloproteinase 2 and 9) in human bladder tumors. Oncol Rep 15: 1321-1326, 2006.

9. Di Carlo A, Terracciano D, Mariano A and Macchia V: Matrix metalloproteinase-2 and matrix metalloproteinase-9 type IV collagenases in serum of patients with pleural effusions. Int $\mathrm{J}$ Oncol 26: 1363-1368, 2005.
10. Triebel S, Bläser J, Reinke $\mathrm{H}$ and Tschesche H: A $25 \mathrm{kDa}$ $\alpha_{2}$-microglobulin-related protein is a component of the $125 \mathrm{kDa}$ form of human gelatinase. FEBS Lett 314: 386-388, 1992.

11. Yan L, Borregaard N, Kjeldsen L and Moses MA: The high molecular weight urinary matrix metalloproteinase (MMP) activity is a complex of gelatinase $\mathrm{B} / \mathrm{MMP}$ and neutrophil gelatinase-associated lipocalin (NGAL). J Biol Chem 276: 37258-37265, 2001.

12. Roy R, Louis GL, Loughlin KR, Wiederschain D, Kilroy SM, Lamb CC, Zurakowski D and Moses MA: Tumor-specific urinary matrix metalloproteinase fingerprinting: identification of high molecular weight urinary matrix metalloproteinase species. Clin Cancer Res 14: 6610-6617, 2008.

13. Goldberg GI, Strongin A, Collier IE, Genrich LT and Marmer BL: Interaction of 92-kDa type IV collagenase with the tissue inhibitor of metalloproteinases prevents dimerization, complex formation with interstitial collagenase, and activation of proenzyme with stromelysin. J Biol Chem 267: 4583-4591, 1992.

14. Russo P: Localized renal cell carcinoma. Curr Treat Options Oncol 2: 447-455, 2001

15. Kashyap MK, Kumar A, Emelianenko N, Kaahyap A, Kaushik R, Huang R, Khullar M, Sharma SK, Singh SK, Bhargave AK and Upadhyava SK: Biochemical and molecular markers in renal cell carcinoma: an update and future prospects. Biomarkers 10: 258-294, 2005.

16. Struckmann K, Mertz K, Steu S, Storz M, Staller P, Krek W, Schraml P and Moch H: pVHL co-ordinately regulates CXCR4/ CXCL12 and MMP2/MMP9 expression in human clear-cell renal cell carcinoma. J Pathol 214: 464-471, 2008.

17. Kallakury BV, Karikehalli S, Haholu A, Sheehan CE, Azumi N and Ross JS: Increased expression of matrix metalloproteinases 2 and 9 and tissue inhibitors of metalloproteinases 1 and 2 correlate with poor prognostic variables in renal cell carcinoma. Clin Cancer Res 7: 3113-3119, 2001.

18. Abdel-Wahed MM, Asaad NY and Aleskandarany M: Expression of matrix metalloproteinase-2 in renal cell carcinoma. J Egypt Nat Canc Inst 16: 168-177, 2004.

19. Kugler A, Hemmerlein B, Thelen P, Kallerhoff M, Radzun HJ and Ringert RH: Expression of metalloproteinase 2 and 9 and their inhibitors in renal cell carcinoma. J Urol 160: 1914-1918, 1998.

20. Kamiya N, Kishimoto T, Suzuki H, Sekita N, Nagai Y, Oosumi N, Kito H, Tochigi N, Shinbo M, Nemori R, et al: increased in situ gelatinolytic activity in renal cell tumor tissues correlates with tumor size, grade and vessel invasion. Int J Cancer 106: 480-485, 2003.

21. Lein M, Jung K, Laube C, Hübner T, Winkelmann B, Stephan C Hauptmann S, Rudolph B, Schnorr D and Loening SA: Matrixmetalloproteinases and their inhibitors in plasma and tumor tissue of patients with renal cell carcinoma. Int $\mathrm{J}$ Cancer 85: 801-804, 2000.

22. Cannon GM and Getzenberg RH: urinary matrix metalloproteinases activity is not significantly altered in patients with renal cell carcinoma. Urology 67: 848-850, 2006.

23. Sherief MH, Low SS, Miura M, Kudo N, Novick A and Weimbs T: Matrix metalloproteinase activity in urine of patients with renal cell carcinoma leads to degradation of extracellular matrix proteins: possible use as a screening assay. J Urol 169: 1530-1534, 2003. 